\title{
La diversificación de estrategias socioambientales en la familia campesina: mecanismo de resiliencia ante la crisis del café en Chiapas
}

\section{Diversifying Socio-Environmental Strategies within the Small-Scale Farming Family: A Mechanism of Resilience Face the Chiapanecan Coffee Crisis}

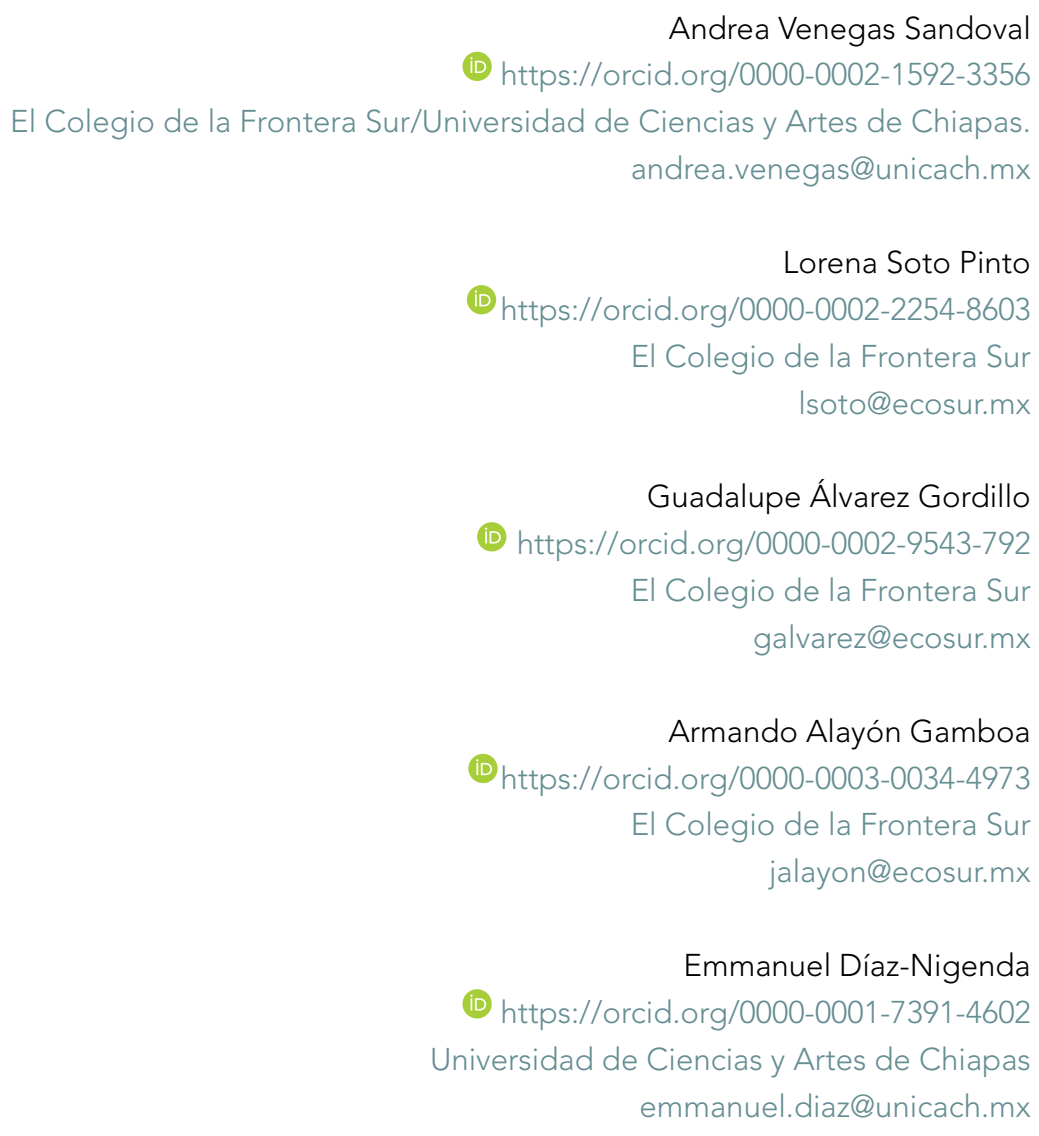

Resumen

Las familias campesinas productoras de café se han enfrentado a una serie de problemáticas recurrentes. Ante esta situación, las familias implementaron estrategias que les permiten recuperarse y persistir buscando su bienestar. El objetivo de este estudio fue analizar la diversificación como un mecanismo que opera en el sistema socioambiental de café y que determina el establecimiento de estrategias familiares para lidiar con las amenazas. Para ello, se analizó la información de 100 entrevistas que se realizaron en 28 localidades en la región de la Sierra Madre del Sur de Chiapas. Se identificaron cinco estrategias principales de diversificación que pueden fortalecer la resiliencia del sistema socioambiental.

Palabras clave: pluriactividad, caficultura, sistema socioambiental, diversidad, roya del cafeto 
Abstract

Small-scale coffee-producing families have been confronting a series of recurring issues. Facing this situation, the families have implemented strategies to enable them to recover and persist in their search for well-being. The goal of this study was to analyze diversification as a mechanism operating within the socio-environmental coffee-producing system which defines the establishment of family strategies to deal with the threats they are facing. Information was analyzed from 100 interviews carried out in 28 locations in the region of the Sierra Madre del Sur mountain range in Chiapas State. Five main diversification strategies were identified that might strengthen the resilience of this socio-environmental system.

Keywords: pluriactivity, coffee growing, socio-environmental system, diversity, coffee leaf rust

Recibido: 11/05/2020

Aceptado: 16/10/2020

Publicado:13/05/2021

\section{Introducción}

La historia de la producción y comercialización del café por parte de las familias campesinas en México refleja un proceso continuo de problemas económicos, sociales y ambientales que pueden analizarse como ciclos de renovación adaptativa. Entre los problemas destacan la volatilidad del precio del café, los impactos climáticos en la productividad y el ataque de plagas y enfermedades (Eakin, Tucker, Castellanos, Díaz-Porras, Barrera y Morales, 2013). Además, se presentan complicaciones en la salud humana, migración de los caficultores jóvenes, degradación de suelos y reducción de los rendimientos del café (Nájera 2002; Santacruz y Pérez, 2009; Figueroa, Pérez y Godínez, 2015).

Adicionalmente, en el escenario de una economía neoliberal, estas familias son presionadas por el agronegocio y abandonadas por el Estado. El primero, extrae el valor de su tierra y su trabajo. El segundo los desampara, pues ha reducido los apoyos al campo en las últimas décadas (Villafuerte, 2015). En este contexto, y para hacer frente a esta compleja problemática, las familias campesinas productoras de café implementaron diferentes estrategias que les permiten recuperarse y persistir en la búsqueda de su bienestar (Hausermann, 2014). Estas estrategias constituyen un conjunto de procesos que las familias desarrollan, consciente o 
inconscientemente, con el objetivo de garantizar la reproducción y/o el mejoramiento de las condiciones de vida en las zonas cafetaleras (Chayanov, 1974; Bourdieu, 2002; Aguilar-Støen, Angelsen, Stølen y Stein, 2011; Eakin, Bojórquez, Monterde, Castellanos y Haggar, 2011; Ayala-Carrillo, Zapata, Suárez y Nazar, 2014; Rodríguez y Burger, 2015; Bathfield, Gasselin, García, Vandame y López, 2015; Ward, Gonthiera y Nicolls, 2017; Valencia, García, Sterling, West, Meza y Naeeme, 2018). Las estrategias campesinas pueden fortalecer o debilitar la resiliencia del sistema -integrado por la familia y sus agroecosistemas-. El fortalecimiento de la resiliencia depende de que estas estrategias permitan la adaptación o transformación ante las circunstancias intrínsecas y del entorno.

Existen diversas perspectivas de análisis para aproximarse al estudio de la resiliencia: psicológica (Kalawski y Haz; 2003); social (Adger, 2000); ecológica (Gunderson, Holling, Pritchard y Peterson, 2002; Perz, Muñoz, Kiker y Holt, 2013) y socioecológica (Walker, Holling, Carpenter y Kinzig, 2004; Folke, 2006; Biggs, Schluter y Schoon, 2015). En este estudio se usará la resiliencia socioecológica como perspectiva de análisis.

La resiliencia socioecológica se define como la capacidad de un sistema de permanecer, mantener y/o fortalecer sus funciones agroecosistémicas y el bienestar social después de someterse a alguna perturbación -como la disminución del precio de los productos, el ataque de plagas y enfermedades o los efectos de fenómenos meteorológicos-. Esto es posible a través de diferentes mecanismos que permiten el amortiguamiento de los impactos, también mediante respuestas de adaptación o transformación de la familia y su cafetal, como han propuesto otros autores para sistemas socioambientales (Walker et al., 2004; Biggs et al., 2015).

A su vez, las estrategias campesinas que influyen sobre la resiliencia del sistema dependen de distintos mecanismos sociales, los cuales son definidos como los procesos que ocurren y que son capaces de facilitar o impedir transformaciones (cambios y continuidades estratégicas) en la configuración y funcionamiento de un sistema social (Bunge, 2000; Gross, 2009; Gibert, 2014; González, 2016). Los mecanismos sociales permiten comprender y explicar las creencias, actitudes y acciones que presenta un grupo social (Pierson, 2000; Hedström, 2006; Boudon, 2006). Por lo que son útiles para entender las estrategias que implementan las familias campesinas y su repercusión en la resiliencia (Folke, Berkes y Colding, 1998; Olsson, Folke y Hahn, 2004; Tompkins y Adger, 2004; Buchmann, 2009; Bacon, Sundstrom, Stewart y Beezer, 2017). 
El estudio de las respuestas de las familias campesinas -a través de marcos conceptuales y metodológicos como el de los mecanismos sociales- contribuye para identificar las estrategias que permiten la resistencia, persistencia y resiliencia del sistema (Arteaga, 2007; Altieri, 2013). Ejemplos de mecanismos sociales son la formación de creencias, la coordinación, la innovación tecnológica y la diversificación en los sistemas (Bunge, 2000; Bunge, 2004; Hedstrom y Swedberg, 2006; Buchman, 2009; Falleti y Lynch, 2009; González, 2016).

El mecanismo de formación de creencias ocurre cuando una familia adquiere nuevos conocimientos, los cuales emergen al reunirse con otras personas, al compartir experiencias y tomar decisiones que se suponen efectivas ante las crisis, esto en función de la valoración de las nuevas ideas y acciones provenientes de aquellas personas (Falleti y Lynch, 2009; González, 2016). También, el mecanismo social de coordinación se presenta cuando integrantes de una comunidad realizan una acción o adoptan una estrategia en función de que otros se sumen a la acción. Debe entenderse que el beneficio aumenta en relación a cuantas más personas ejecutan la misma acción (Pierson, 2000; Falleti y Lynch, 2009; Frank, Eakin y López, 2011). El mecanismo de innovación tecnológica, por su parte, es un proceso gradual de selección y transformación de ideas, objetos, experiencias y/o actividades para la conformación de productos, innovaciones o nuevos procesos productivos en respuesta a problemas complejos (Renau, 1977; Bunge, 2000; Levy et al., 2012; Van Oostrom y Fernández-Esquinas, 2017).

El mecanismo de diversificación ha sido estudiado desde diferentes perspectivas teóricas dando lugar a distintas acepciones (Mora y Cerón, 2015), en la más amplia: es el proceso de promover o aumentar la variedad de una realidad (Toledo y Barrera-Bassols, 2008). Desde la sociología rural, se le concibe como la pluriactividad que permite a las familias campesinas resistir contra la pobreza (Carton de Grammont y Martínez, 2009). Por otro lado, Ellis (1998) define diversificación como el proceso por el cual las familias realizan una variedad de actividades y utilizan distintos recursos sociales para resistir o mejorar sus condiciones de vida. Estas definiciones conciben la diversificación desde una perspectiva amplia, debido a que consideran la diversidad de estrategias que utilizan las familias y no solo se limitan a examinar las distintas fuentes de ingreso (Mora y Cerón, 2015). Buchman (2009) al estudiar la contribución de los huertos a la resiliencia socioecológica de los hogares cubanos, identifica la diversificación como un mecanismo social que incide en la resiliencia del sistema. En su estudio, es un mecanismo 
que consiste en la utilización de distintos recursos: sociales, físicos, naturales, financieros y humanos. Asimismo, el empleo de los recursos es mediado por los valores y la cultura.

En este marco, se busca responder a las siguientes preguntas: ¿Cómo se presenta el mecanismo social de diversificación en las estrategias que implementan las familias campesinas caficultoras para hacer frente a la roya? y ¿Cuál es la influencia de las estrategias de diversificación en la resiliencia del sistema?

El objetivo de este estudio fue analizar la diversificación como mecanismo social que opera en el sistema socioambiental de café y que determina el establecimiento de estrategias campesinas, desde el ámbito de la parcela a través de las prácticas para mantener la diversidad, hasta el ámbito familiar con las estrategias de diversificación de actividades y fuentes de ingreso que influyen en la resiliencia del sistema. El resultado de esta investigación contribuye tanto con el análisis de la diversificación como con la identificación de procesos que generan resiliencia en la caficultura campesina, enfocándose en el estudio de las estrategias campesinas desarrolladas para enfrentar la última epidemia de la roya del cafeto (Hemileia vastatrix Berkeley \& Broom). La epidemia fue una emergencia que afectó de forma severa a los cafetales entre 2012 y 2016 y redujo significativamente la producción del grano (Barrera, Huerta, Herrera, Gómez y Avelino, 2013; Pérez-Pérez y Villafuerte-Solís, 2018). En respuesta a los impactos que generó en la caficultura, esperaríamos el despliegue de distintas estrategias de diversificación por parte de las familias, las cuales inciden en la resiliencia de la caficultura campesina.

\section{Metodología}

\section{Área y sujeto de estudio}

El estudio se realizó con familias de caficultores de seis diferentes cooperativas, asociadas todas a una federación de organizaciones denominada Federación de Indígenas Ecológicos de Chiapas (FIECH). La edad promedio de los caficultores es de 53 años, con una historia de 29 años dedicados a la caficultura, de los cuales, en promedio, han participado 17 años en cooperativas y nueve han cultivado el café bajo el esquema de producción orgánica. Se seleccionaron 30 localidades productoras de café de la región de la Sierra Madre del Sur de Chiapas, México, en los municipios de Amatenango de la Frontera, Bellavista, Escuintla, Frontera Comalapa, Huixtla, Montecristo de Guerrero, Tapachula y Tuzantán (véase Figura 1). 
El área en cuestión presenta climas cálido húmedo, cálido subhúmedo y semicálido húmedo (Instituto Nacional de Estadística y Geografía, 2008). Con suelos de los grupos Fluvisol, Phaeozem, Leptosol, Luvisol, Acrisol, Regosol y Cambisol (INEGI, 2014) cuyos principales usos son: urbano, agricultura de temporal, pastizal inducido, vegetación secundaria y relictos de vegetación de selva mediana y alta perennifolia, así como de bosque mesófilo de montaña (CONABIO, 2016; INEGI, 2017). La mayoría de las localidades se encuentran clasificadas con grado de marginación alto y, una de ellas, muy alto (SEDESOL, 2013).

Figura 1. Localización del área de estudio

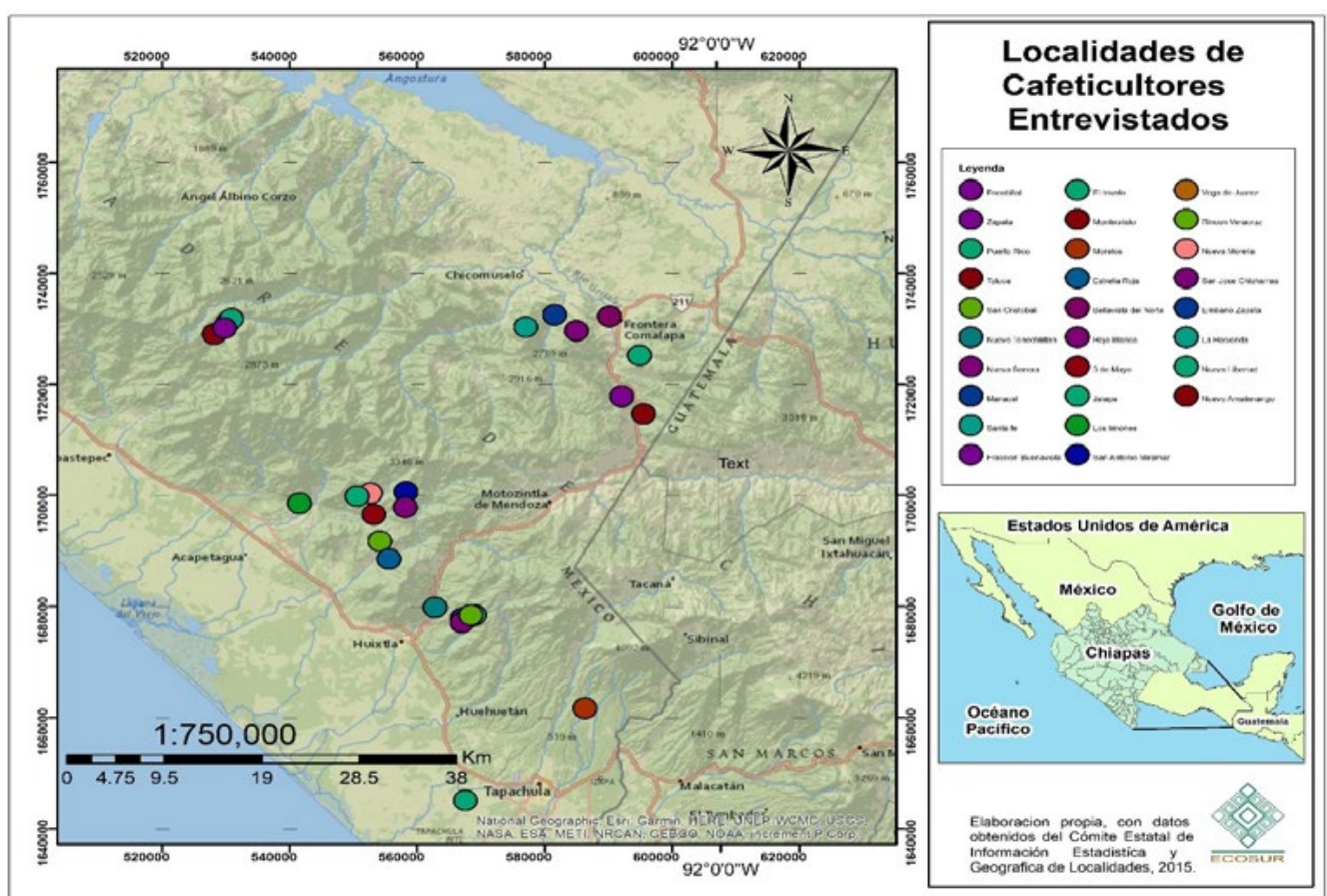

Fuente: Elaboración propia con datos obtenidos de CEIEG, 2015

\section{Selección de la muestra}

Al momento del trabajo de campo, la FIECH contaba con alrededor de 3000 productores de 248 comunidades de 25 municipios de Chiapas. Por ello, esta Federación representaba una de las más importantes agrupaciones de caficultores del estado. Cabe destacar que los directivos de la FIECH manifestaron interés en colaborar para la realización del presente estudio. Se decidió trabajar en la región de la Sierra Madre del Sur de Chiapas por la relevancia de la zona para la caficultura y por su contexto histórico, productivo y de comercialización. 


\section{Recolección de datos}

Entre mayo de 2015 y agosto de 2016 se aplicaron entrevistas estructuradas a 143 caficultores (52 mujeres y 91 hombres) de 28 localidades (véase Figura 1). Para el análisis se utilizaron 100 de las 143 pues se descartaron las entrevistas confusas e incompletas. Las entrevistas estructuradas recabaron información sobre: la estructura familiar, participación en organizaciones, superficie y usos de la tierra, cultivos producidos, prácticas de manejo implementadas para el cultivo del café, principales problemas percibidos por las familias y sus respuestas ante estos. Las entrevistas fueron grabadas (previo consentimiento informado) y transcritas para realizar el análisis de contenido. Además de las entrevistas, se llevó a cabo observación participante. Para ello, se visitaron los cafetales y los hogares de los caficultores y se asistió a dos reuniones de trabajo de la federación cafetalera y a cuatro foros y talleres participativos a los que acudieron caficultores, académicos

y representantes de instituciones gubernamentales. Asimismo, se complementó la información con cinco entrevistas informales y semiestructuradas con productores, personal técnico y directivos de las organizaciones en el marco de diversas reuniones de trabajo de la federación cafetalera.

\section{Análisis de la información}

Con el fin de analizar la información que generaron las entrevistas estructuradas, se elaboraron bases de datos para realizar análisis estadísticos descriptivos que fueron procesados en Microsoft Excel (versión 2001) y SPSS 15.0 para Windows. Se obtuvieron las frecuencias de las respuestas y se realizó un análisis de chi cuadrado $\left(x^{2}\right)$ para examinar la relación existente entre la producción de café (cantidad de café cosechado en el ciclo 2015-2016) y la pluriactividad (número de fuentes principales de ingreso). También se llevó a cabo un análisis del contenido con las transcripciones de los audios de las entrevistas. La copia de la grabación a escrito sirvió para identificar la situación actual del sistema socioambiental cafetalero, las características de las familias, las estrategias y mecanismos sociales que operan como respuestas de las familias campesinas y su aporte a la resiliencia, para lo cual se utilizó el software QSR N6 (QSR Internacional, 2002). 


\section{Resultados}

\section{El sistema socioambiental del café y sus mecanismos sociales}

El sistema socioambiental del café está conformado por la unidad doméstica (generalmente familias nucleares) y sus agroecosistemas (cafetal, milpa, huerto, potrero, acahuales). Las familias cuentan con seis hectáreas (ha) de tierra en promedio, de las cuales destinan cuatro para la producción de café. Así configurado, el cultivo del café está estrechamente relacionado con la organización familiar, donde el trabajo de hombres y mujeres es fundamental para su producción. Las familias, la mayoría nucleares, están constituidas por cinco integrantes en promedio. En 43 \% de estas, al menos un/a hijo/a colabora con las actividades de la caficultura.

Se observa una distribución de las tareas por sexo. Los hijos se dedican a las actividades de mantenimiento de viveros, poda, manejo de sombra, resiembra, cosecha, despulpado, lavado y secado del grano. Las hijas trabajan en la cosecha, despulpado, lavado y secado del grano, llevan la contabilidad familiar y preparan los alimentos. Sobre las mujeres adultas, $16 \%$ de los entrevistados señaló que sus esposas trabajan en distintas etapas de la producción del café. Principalmente en la cosecha, secado y lavado del grano, así como en otras actividades reproductivas como la preparación de los alimentos -para la familia y los trabajadores del cafetal-, el trabajo doméstico y de cuidados, educación y salud de los distintos integrantes de la familia. Ahora bien, sobre la organización en asociaciones se argumentaron diferentes ventajas. En orden de frecuencia, se señalaron las siguientes: motivos económicos, por recibir el sobreprecio debido a las calidades especiales del café orgánico y el comercio justo; recibir asesorías, capacitaciones, insumos (abono y/o plantas) o herramientas; deseo de pertenecer a una organización y sentimiento de orgullo por producir café de forma limpia y/o justa, a través de la producción orgánica. El siguiente testimonio lo confirma: «...las razones son que estar organizado ahí se aprovechan muchas cosas: algunos cursos, lo que es café, eventos como algunos foros que se lleva. Más que nada por la exportación de café, que no queremos caer con el coyote» (Caficultor, 64 años).

Algunos productores (6\%) señalan que pertenecen a una organización por invitación de algún familiar; otros mencionan que se incorporaron con la finalidad de alcanzar un objetivo -una acción colectiva-, ya sea para aumentar la producción de 
café o para lograr la adquisición de tierras: «como ahorita, pues, estamos trabajando las tierras, nuestro propósito es ganar las tierras, no somos dueños todavía» (Caficultor, 27 años). En este sentido, la participación en cooperativas fortalece la capacidad de agencia de los caficultores. De acuerdo con las respuestas, el sistema socioambiental del café es susceptible a distintas perturbaciones. Entre las principales se encuentran: la incidencia de plagas y enfermedades (el $96 \%$ de los entrevistados las señalan como uno de los problemas centrales), el impacto de fenómenos climáticos (sequía, altas temperaturas y lluvias intensas) (36 \%), la escasez de recursos económicos (33 \%), precios bajos pagados al productor por la compra del grano (20\%), falta de fuerza de trabajo (10\%), políticas mal dirigidas (9\%) y falta de asistencia técnica (7\%). Ante tales problemáticas, pocos productores (17 \%) permanecieron pasivos. El resto realizó alguna acción en respuesta a ellas. Estas acciones representan estrategias influenciadas por los mecanismos sociales que operan en el sistema. Los mecanismos sociales identificados en el sistema cafetalero que influyen en las estrategias familiares y que impactan en su resiliencia son: formación de creencias, coordinación, innovación tecnológica y diversificación. Este último y sus estrategias se representan en la Figura 2.

Figura 2. Mecanismo social de diversificación y estrategias en el sistema socioambiental de la familia cafetalera.

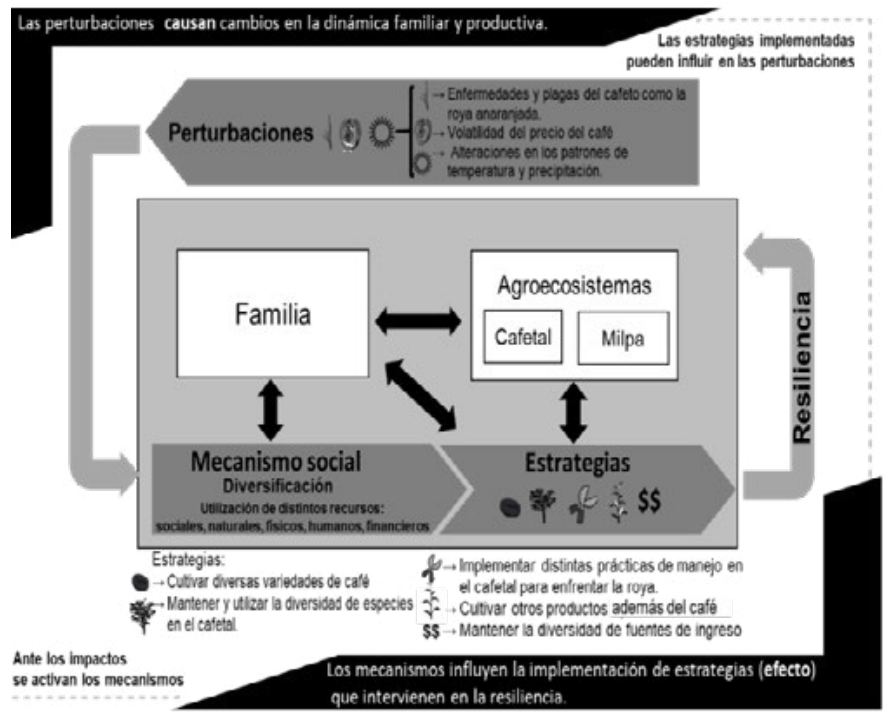

Fuente: Elaboración propia a partir de observaciones de campo 
El mecanismo de formación de creencias ante una emergencia-como la roya del cafeto- se manifiesta en la toma de decisiones y acciones, por ejemplo la renovación con variedades de café tolerantes a dicha enfermedad, motivada por los comentarios y las acciones emprendidas por personas vecinas, familiares y compañeros de organización. Los productores realizan renovación por la creencia de que este cambio traerá como consecuencia el aumento de los rendimientos y la eliminación permanente de la roya del cafeto. El mecanismo social de coordinación se observa al incrementarse la adopción del cultivo de café orgánico en las comunidades conforme crece la organización que comercializa este tipo de café y su incidencia. El mecanismo de innovación en la caficultura es, por ejemplo, la utilización de caldos de microorganismos benéficos como alternativa al uso de agroquímicos, aunque existen múltiples ejemplos de procesos de este tipo en la historia de la caficultura campesina. El mecanismo social de diversificación se observa en el desarrollo de diferentes estrategias que permiten aumentar y utilizar distintos acervos: 1) diversidad de fuentes de ingreso; 2) distintas formas de uso del suelo (cafetal orgánico, convencional, milpa, huerto familiar, bosque y potrero); 3) variedad de prácticas para hacer frente a la roya; 4) manejo de la diversidad de especies en el cafetal y 5) cultivo de diversas variedades de café. Estas estrategias se implementan a diferentes escalas espaciales y temporales (véase Figura 2 y 3 ).

Figura 3. Estrategias de diversificación en el sistema socioambiental del café

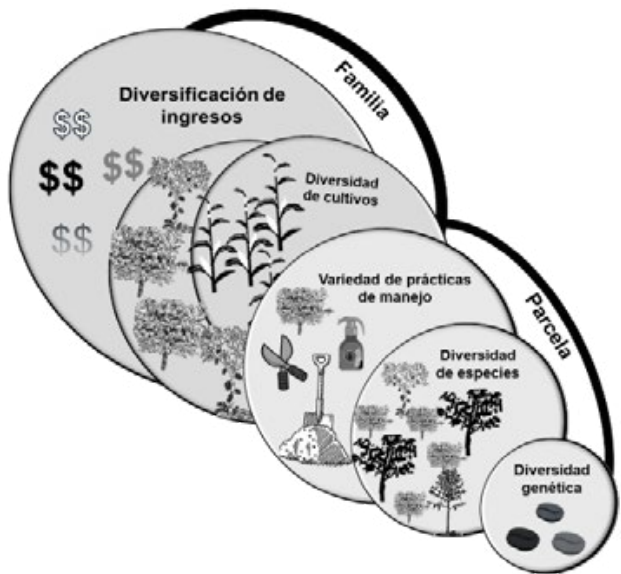

Fuente: Elaboración propia a partir de observaciones de campo 


\section{Diversificación de ingresos}

La caficultura es la principal fuente de ingresos en la región. Los siguientes testimonios demuestran la importancia del café y de la estrategia de diversificación de actividades, ingresos y productos:

...aquí, en nuestro municipio, vive la gente del café; el maíz se siembra para nuestro consumo. La mayoría de las personas que producían mucho café es de donde sacaron dinero para mantener a sus hijos para sus estudios, muchos de aquí lograron una carrera, pero a base del café, les ha ayudado. Algunos con su negocio, pero más el café que ha ayudado a mucha gente... (Caficultor, 53 años)

...trabajamos con hortalizas, trabajamos también con el hongo seta... y luego la cría de cabras. Vendemos los machos y también la leche. No hemos hecho el intento de hacer queso de cabra, pero lo vamos a aprender. Eso y con la cría de gallinas de traspatio y lombricultura... (Caficultor, 64 años).

Podemos observar que $52.1 \%$ de los entrevistados obtiene recursos económicos de dos o más fuentes de ingreso, entre las que destacan: la agricultura, el trabajo asalariado, el comercio (abarrotes), las remesas y la ganadería (véase Cuadro 1). De los productores que se dedican únicamente a la agricultura, $56 \%$ vende otros productos agrícolas además del café.

Los programas gubernamentales en los que se puede encontrar un beneficio económico son «Prospera» y «Setenta y más» (actualmente denominado: «Programa para el Bienestar de los Adultos Mayores»). En menor proporción se encuentran los apoyos productivos otorgados por instituciones como la Secretaría de Agricultura y Desarrollo Rural (SADER) y por la Comisión Nacional Forestal (CONAFOR). Estos programas gubernamentales constituyen una alternativa de ingreso económico que contribuye a la economía familiar campesina, que incluso en ocasiones se convierte en la principal fuente de ingreso, como lo señaló un caficultor.

En el $43.6 \%$ de familias, el ingreso no agrícola es un complemento, más que un sustituto; solo $6.4 \%$ de caficultores no mencionan entre sus principales fuentes de ingreso la agricultura. $14.9 \%$ de los caficultores señaló que una fuente importante de ingresos proviene de las remesas que reciben de familiares migrantes (véase Cuadro 1). Aunque las familias despliegan una diversidad de estrategias para complementar su ingreso, las tres principales fuentes que les aportan mayor retribución (véase Cuadro 1) no influyeron sobre los distintos niveles de producción del café durante el ciclo 2015-2016 ( $x^{2}=7.9$; $P=0.63$, véase Cuadro 2). 
Cuadro 1. Principales fuentes de ingreso entre los caficultores de la región de estudio

\begin{tabular}{ccc} 
Número de fuentes & Actividad & Caficultores (\%) \\
\hline \multirow{2}{*}{ Una } & Agricultura & 44.7 \\
& Trabajo asalariado & 2.1 \\
& Apoyo del gobierno & 1.1 \\
\hline \multirow{2}{*}{ Dos } & Agricultura y trabajo asalariado & 14.9 \\
& Agricultura y comercio & 11.7 \\
& Agricultura y remesas & 6.4 \\
& Agricultura y ganadería & 5.3 \\
& Trabajo asalariado y comercio & 2.1 \\
Trabajo asalariado y remesas & 1.1 \\
\hline & Agricultura, comercio y remesas & 5.3 \\
& Agricultura, trabajo asalariado y comercio & 2.1 \\
& Agricultura, trabajo asalariado y remesas & 2.1
\end{tabular}

Fuente: Información obtenida de las entrevistas aplicadas a los caficultores

Cuadro 2. Cuadro de contingencia: número de actividades * nivel de producción

\begin{tabular}{|c|c|c|c|c|}
\hline \multirow{2}{*}{$\begin{array}{l}\text { Nivel de producción (p) en el ciclo 2015- } \\
\qquad 2016\end{array}$} & \multicolumn{3}{|c|}{ Número de fuentes de ingreso } & \multirow{2}{*}{ Subtotal } \\
\hline & Uno & Dos & Tres & \\
\hline $\begin{array}{l}\text { Producción marginal } \\
(\leq 700 \mathrm{~kg})\end{array}$ & 25 & 30 & 7 & 62 \\
\hline $\begin{array}{l}\text { Muy baja productividad } \\
\quad(700<\mathrm{p} \leq 1,400)\end{array}$ & 6 & 4 & 3 & 13 \\
\hline $\begin{array}{l}\text { Baja productividad } \\
(1,400<\mathrm{p} \leq 2,100 \mathrm{~kg})\end{array}$ & 6 & 4 & 1 & 11 \\
\hline $\begin{array}{c}\text { Intermedio } \\
(2,100<p \leq 2,800 \mathrm{~kg})\end{array}$ & 2 & 2 & 0 & 4 \\
\hline $\begin{array}{c}\text { Productivo } \\
(2,800<\mathrm{p} \leq 3,500 \mathrm{~kg})\end{array}$ & 3 & 0 & 0 & 3 \\
\hline $\begin{array}{l}\text { Buena productividad } \\
\quad(>3,500 \mathrm{~kg})\end{array}$ & 2 & 1 & 1 & 4 \\
\hline & & & TOTAL & 97 \\
\hline
\end{tabular}

Nota al pie: En tres de las 100 entrevistas utilizadas para el análisis, los productores no proporcionaron información respecto a la cantidad de café cosechado en el ciclo 2015-2016, razón por la cual se utilizó la información de 97 caficultores.

Fuente: Información obtenida de las entrevistas aplicadas a los caficultores

64\% de los caficultores señalaron que en el ciclo 2015-2016 su producción fue marginal ( $\leq 700 \mathrm{~kg}$ ); $88.6 \%$ manifestaron que sus cafetales presentaban de baja a marginal producción (véase Cuadro 2). Esto debido, principalmente, a las consecuencias de la epidemia de la roya. Sin embargo, a pesar de estas condiciones, 
los caficultores expresaron su interés en enfrentar la situación y continuar cultivando café, como lo demuestra el siguiente comentario: «la crisis de la roya ha resultado en un mal necesario ya que ha obligado a buscar producción agroecológica...Si vamos a transformar a la planta primero nos debemos transformar nosotros» (Caficultor, 52 años). Además, el hecho de que $97 \%$ había iniciado procesos de renovación de sus cafetales, muestra que siguen con la expectativa de cultivar café debido a que la renovación representa una inversión de recursos que reditúa a mediano o largo plazo.

\section{Diversidad de usos de suelo}

$48 \%$ de las familias posee parcelas para la producción de café y parcelas destinadas a la milpa (producción de maíz, frijol, calabaza, yuca, chiles, camote y otras especies de palmas, tubérculos, hierbas comestibles y frutales). La milpa representa un sustento importante de la alimentación, no obstante, un grupo importante $(42 \%)$ de caficultores especializados no tiene milpa y satisface su demanda de maíz a través de la compra de productos básicos en la misma comunidad o en mercados regionales. Más de la mitad de los caficultores (58\%) tiene tierras que destina para usos de suelo diferentes a la producción de café, entre ellos se encontró que las dedican a la producción de alimentos y ganadería, principalmente de traspatio (véase Figura 4).

Figura 4. Variedad de usos de suelo

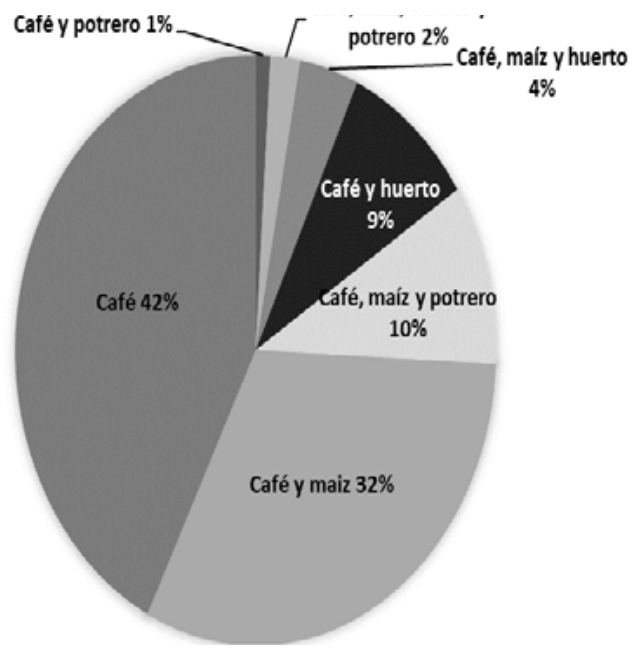

Fuente: Elaboración propia 
De acuerdo con las observaciones en campo, el área que algunos productores tenían en sus espacios de residencia destinados a solares o a huertos se remplazó por viveros para las plántulas de café o patios de secado.

\section{Variedad de prácticas para hacer frente a la roya}

Se encontró que el grado de afectación de los cafetales por la roya era variable entre las distintas localidades visitadas. A pesar de esto, la gran mayoría manifestó daños por esta enfermedad (96\%). Por consiguiente, enfrentaron la reducción en la producción del grano de café. Al respecto, algunos entrevistados expresaron lo siguiente: «Lo terminó la roya nuestro café»... «Nos esclavizó la roya»... «Me da lástima tirar mi café»... «Estamos acostumbrados a recibir dinero del café»....

Ante esta situación, las familias reportaron distintas prácticas agronómicas en sus parcelas, entre las que destacan:

a) La fumigación con productos orgánicos y aplicación de caldo preparado domésticamente con «microorganismos benéficos» (al parecer organismos fúngicos, bacterias fijadoras de nitrógeno y entomopatógenos, a los cuales etiquetan como: «Beauveria», «Azotobacter», «Micorrizas» y «organismos de montaña»). Los preparan ellos mismos con asesoría de instituciones académicas y organizaciones de productores.

b) La renovación del cafetal con variedades resistentes a la roya.

c) El manejo cultural, es decir, de los tejidos (podas, deshijes, recepas), abonado, deshierbes, prácticas de conservación del suelo y manejo de la sombra (desramado, selección y eliminación de árboles).

Estas prácticas son probadas por los productores y aplicadas una vez que han demostrado los beneficios. Los productores toman decisiones según subjetividades, costos y recomendaciones de personas con quienes interactúan, como muestra este testimonio:

...mira, con el café siempre ha habido muchos problemas, esta variedad de porte bajo, lo que es el Catimor... si tenemos mucha sombra, se enferma la planta por el frío, por la humedad; si nosotros quitamos mucha sombra, esas plantas se deterioran por el calor. Uno le va buscando...cuando empecé a trabajar, al principio, empezamos haciendo aboneras, pero es muy complicado hacer aboneras, porque a veces que no se adquiere el material tal como es, posteriormente empecé a trabajar con lombricultura, ya incrementé 
a través de una cría de cabras y una cría de gallinas ... y toda la excreta de los animales como las cabras, las gallinas, los conejos... todo se va a la lombricultura, todo ese abono lo aprovecho en dos partes: el abono sólido y el líquido...también ahorita estamos aplicando los microorganismos, hacemos una mezcla y ya lo llevamos a la plantación y nos ayuda a fortalecer las plantas. Lo que venimos también aplicando es el sulfocálcico para control de la roya. Hay que buscarle para mejorar la plantación... (Caficultor, 64 años).

Además de las prácticas agronómicas, los productores piden asesoría y solicitan créditos para invertir en la plantación para enfrentar las recurrentes problemáticas o para salir de los compromisos económicos que asume la familia.

\section{Diversidad de especies de sombra y producción de otros cultivos}

Los cafetales son diversos pues no solo consisten en plantas de café. En ellos se encuentran árboles frutales, tubérculos, hierbas comestibles y palmas. Otros más cuentan con huerto familiar en un espacio aledaño a la casa habitación, destinado principalmente para la alimentación, el cultivo de plantas medicinales, para condimentar y ornamentales, además de animales de traspatio.

Se mencionaron 52 especies que los caficultores producen o mantienen en los cafetales (4 ha) para autoabasto del hogar o para la venta, entre las que se encuentran cultivos comerciales, así como una interesante diversidad de plantas promovidas como sombra y asociadas al café, las cuales tienen propósitos alimenticios, maderables, combustibles y medicinales, entre otros. Las especies con mayor mención, en orden de importancia, fueron chalum (Inga sp.), utilizado principalmente como sombra para el café y para leña; distintas variedades de plátano (Musa sp.), naranja (Citrus sinensis (L.) Osbeck) y aguacate (Persea americana Mill.) para autoabasto y comercio local (véase Figura 5). El cacao (Theobroma cacao L.) se identifica como una alternativa complementaria a la caficultura en las zonas bajas. En su mayor medida el cacao es destinado a la comercialización del grano seco. Los entrevistados obtienen ingresos de otros cultivos además del café; el plátano y la naranja son las opciones comerciales más frecuentes.

Asimismo, el aguacate ( $P$. americana), la naranja (C. sinensis) y el limón (Citrus limon) son consideradas por los caficultores como especies preferidas porque pueden adaptarse dentro o fuera del cafetal (véase Figura 5). El manejo de la diversidad de especies en el cafetal es una práctica común entre los caficultores, quienes, por lo general, desean incrementar la diversidad de especies aprovechables, tal como lo muestra el siguiente testimonio: «queremos meterle árboles de aguacate en el cafetal, mango y otros árboles de fruta que nos puedan ayudar» (Caficultor, 64 años). 
Figura 5. Especies cultivadas y de interés para los caficultores

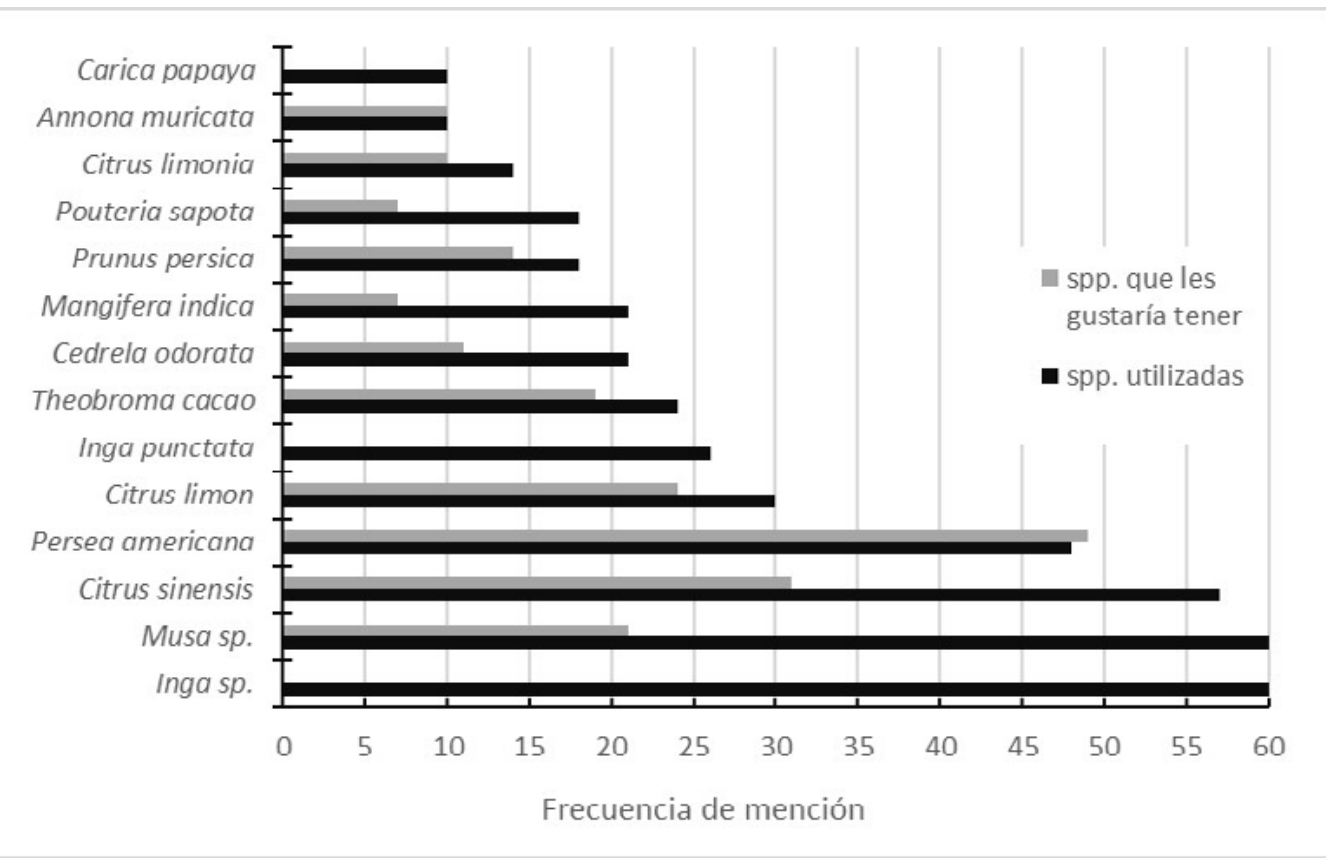

Fuente: Elaboración propia

\section{Diversidad de variedades de café}

Por la avanzada edad de las plantas de café y para mejorar la productividad, desde hace varias décadas los caficultores más organizados renuevan sus cafetales. Sin embargo, a partir del ataque de roya y a raíz de programas de las organizaciones caficultoras, de empresas del agronegocio, del gobierno y por iniciativa propia, los productores renuevan más intensiva y sistemáticamente con variedades resistentes a esta enfermedad. Se encontró que 79 \% de los productores ya había renovado sus cafetales con variedades provenientes del híbrido de Timor (Costa Rica 95, Castillo, Lempira y Oro Azteca, entre otras); en menor grado se renueva con arábigos tradicionales (5\%) o una mezcla de estas (2\%) y otro porcentaje importante (14\%) cambia el sistema a café Robusta (Coffea canephora (P.) ex Froehner). A pesar de que se renuevan los cafetales con variedades resistentes, la variedad que aún tiene mayor presencia en los cafetales es la Típica. Ello debido a que es la más importante en el mercado orgánico (véase Figura 6A) y es la que conocen mejor los productores, como se muestra en el siguiente comentario: 
...el café que siempre se ha cosechado aquí en el país es el Típica, el Bourbon, el Caturra; esos cafés que estamos sembrando apenas (refiriéndose a los híbridos de Timor) no se habían visto, a lo mejor ya estaban; yo apenas me he dado cuenta con esa variedad del café que sí es resistente a la roya, pero no se ha visto todavía el futuro de ese café, de cómo vaya a funcionar. Lo que es el Bourbon, el Marago, pues es el café conocido de hace años... (Caficultor, 53 años).

$89 \%$ de los productores cultiva más de una variedad de café (véase Figura 6B). Es decir, mantiene en sus parcelas mezclas de plantas de café arábigo y cafetos de variedades resistentes. Asimismo, identifica las plantas de las diferentes variedades que presentan mayor tolerancia a la roya y obtiene semillas de estas para sus almácigos. Estas dos prácticas conforman una estrategia de diversificación genética para hacer frente a la roya, como lo refleja el siguiente comentario:

... la roya, cuando se empezó a ver, empecé a trabajar con la renovación de cafetales, le podé toda la plantación y ya empecé a sembrar otras variedades de café resistentes a la roya, metí "Catimor", "Mundo Novo", "Café Pache", "Pluma Hidalgo". Esas variedades empecé a trabajar...ahorita tengo "Catimor", "Pash", "Mundo Novo", este año viene variedad 6, el "Sarchimor" y "Bourbon", como hicimos la renovación: podamos y están saliendo los hijuelos, no quiero perder mi Bourbon porque tiene buen sabor, también Árabe, esperando que esta roya va a pasar, a lo mejor volvamos con el Árabe... (Caficultor 64 años).

Los productores transforman paulatinamente sus parcelas. Pocos son los que cambian sus parcelas de manera radical con una sola variedad. Toman decisiones según el aprendizaje derivado de sus observaciones, de la asesoría técnica recibida y de los comentarios y experiencia de otros caficultores: "... ahorita en mi viverito tengo "Árabe", "Bourbon" y "Catimor", conseguí unas matas de "Guacamayas" pero no sé qué calidad tiene ese café. Pero lo vamos a probar...» (Caficultora, 47 años).

La diversidad de variedades permite a los productores compararlas dentro de su parcela e identificar las que resisten mejor a la roya, así como a otras enfermedades y plagas. Este es un factor de resiliencia por el abanico de respuestas y posibilidades de seleccionar plantas ante las condiciones adversas. Sin embargo, cultivar variedades implica ciertos retos para mantener la eficiencia en la producción. Por ejemplo, la dificultad de cosechar y procesar el café debido a las diferencias en las características del grano, comportamiento ecofisiológico 
y requerimientos técnico-ambientales entre las variedades. Así lo confirma este testimonio: «ahora que cambié de variedad arábiga a Catimor se me hace muy difícil calibrar mi despulpadora, brincan los granos porque el arábigo es más grande y el Catimor más pequeño, eso me da más trabajo» (Productor, 53 años).

Figura 6A y 6 B. Proporción de variedades cultivadas por productores de comunidades de la Sierra Madre del Sur de Chiapas. A) Variedades de café por frecuencia de mención. B) Proporción de productores por variedad

A)

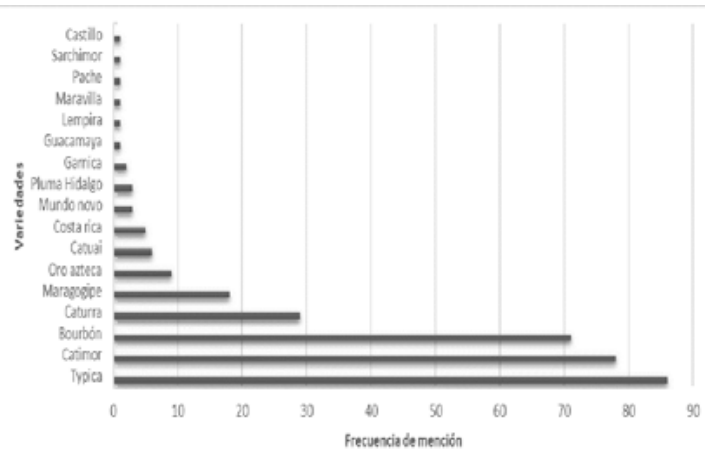

B)

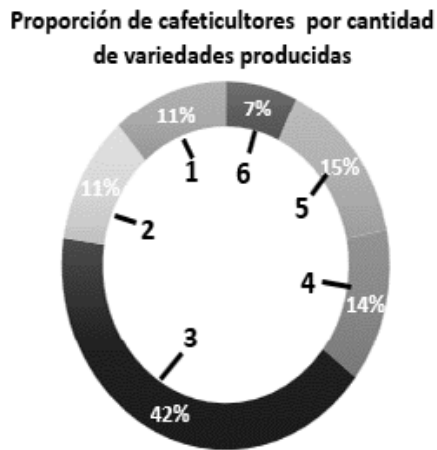

Fuente: Elaboración propia

\section{Discusión}

Los resultados de esta investigación muestran que la persistencia del cultivo de café y la resiliencia de las familias en estas comunidades campesinas ocurre gracias a mecanismos sociales que determinan las estrategias que despliegan. A través de estos mecanismos sociales se pueden comprender y explicar las creencias y actitudes. Como señala González-Jácome (2004), los mecanismos sociales permiten entender la interacción entre cultura y naturaleza en comunidades rurales; asimismo, facilitan la identificación de acciones desarrolladas para enfrentar las recurrentes crisis que ocurren en el medio rural.

Una de estas crisis fue el reciente ataque de la enfermedad de la roya del cafeto, el cual se enfrentó a través de la coordinación entre los integrantes de las familias, cooperativas y dentro la misma comunidad. Los individuos trabajaron en conjunto con innovación tecnológica, las creencias y la diversificación. Estos mecanismos desplegaron estrategias de organización familiar, organización en cooperativas, búsqueda de conocimiento e innovación de prácticas agroecológicas para el cuidado del café, fortalecimiento de los vínculos familiares, comunitarios 
y regionales para compartir información, diversidad de germoplasma, conocimientos, manejo y estrategias de diversificación. La participación en cooperativas les permite reforzar su identidad como caficultores a través del mecanismo de coordinación y formación de creencias, además de que obtienen un sobreprecio por la producción orgánica.

La diversificación es uno de los mecanismos que permite que la mayoría de las familias caficultoras persistan en el cultivo de café a pesar de las múltiples crisis enfrentadas (Henderson, 2019), pero se incorporan procesos de transformación a sus prácticas productivas (implementando variedad de prácticas para hacer frente a la roya y cultivo de diversas variedades de café). De esta manera se mantiene la producción de alimentos a través de distintos agroecosistemas (con diferentes usos del suelo, promoción de diversidad de especies herbáceas, arbustivas, arbóreas y otras formas biológicas en el cafetal para garantizar su seguridad alimentaria) o bien al realizar ajustes a su dinámica familiar (pluriactividad) para mantener su medio de vida. En este sentido, Buchmann (2009) identifica el mecanismo de diversificación en la estrategia de promoción de diversidad de especies alimenticias y medicinales en huertos de familias en Cuba y señala que se incrementa la resiliencia a través del fortalecimiento del capital natural y cultural de la comunidad. Por su parte, Machado-Vargas, Nicholls-Estrada y Ríos-Osorio (2018) identificaron como factores de resiliencia: la diversidad productiva, autonomía y autosuficiencia alimentaria en sistemas cafetaleros en Colombia.

En el caso de esta investigación, la contribución de este mecanismo a la resiliencia dependerá de las condiciones en las que operen las estrategias de diversificación. Es decir, de cómo la familia utilice sus acervos físicos, económicos, naturales, humanos, sociales y culturales. Algunas de estas estrategias no necesariamente tienen como consecuencia mayor productividad de los cafetales o mayor bienestar en la familia, en ocasiones derivan en vulnerabilidad y disparan nuevos ciclos de ruptura, como es el caso del cambio de variedades tradicionales (Típica, Bourbon, Marago, etc.) por las tolerantes a la roya, o bien la disminución de la sombra en los cafetales, o la migración de integrantes de la familia, lo cual provoca cambios en la dinámica familiar. Como señala Henderson (2019), la renovación con variedades tolerantes es una transformación del sistema socioambiental que presenta una transición del cultivo extensivo bajo sombra a un manejo más intensivo con menos sombra, lo que puede hacer al sistema más susceptible a presentar estrés hídrico ante altas temperaturas y al ataque de otras plagas y enfermedades como es el caso del ojo de gallo causada por el hongo Mycena citricolor (Berk \& M.A.Curtis). 
El cultivo y comercialización del café ha representado un medio para la obtención de ingresos para las familias campesinas (Pérez-Pérez y Villafuerte-Solís, 2018). Sin embargo, el porcentaje de la contribución del café al ingreso familiar es fluctuante debido a la comercialización del café para exportación que depende de los precios de venta (Sánchez, 2015) fijados a nivel internacional. En la historia de la caficultura, la fluctuación de los precios ha sido constante y se han producido caídas abruptas de los precios en el mercado internacional que han representado crisis recurrentes (Escamilla et al., 2005). Ante esto, la diversificación de ingresos es un factor importante de resiliencia para los caficultores. Las familias cafetaleras optan por múltiples fuentes de ingreso además de mantener diversidad de usos del suelo, lo que les permite obtener granos básicos, tener animales de trabajo y numerosos productos alimenticios, medicinales y con otros usos domésticos. La diversificación de actividades o pluriactividad campesina aumenta el potencial de incrementar los ingresos, pero tiene sus propias contradicciones. Por ejemplo, el trabajo extracomunitario cuando implica migraciones a otra entidad federativa o a otro país, reduce la cohesión familiar, la conservación de las tradiciones, el mantenimiento de la lengua (en caso de lenguas indígenas), desdibuja las costumbres y los conocimientos locales, cambia la dieta y la vida comunitaria caracterizada por relaciones de solidaridad, ayuda mutua y trabajo colectivo, como se ha reportado en trabajos previos (Carton de Grammont, 2016; Pérez, 2018), lo cual puede tener implicaciones en el debilitamiento de la resiliencia del sistema.

La pluriactividad campesina extracomunitaria es un fenómeno asociado a la desagrarización del campo, que consiste en la disminución del aporte de las actividades agrícolas al ingreso familiar, aunado al incremento de la migración y envejecimiento del campo, lo cual repercute en la permanencia campesina (Escalante, Catalán, Galindo y Reyes, 2007; Jarquín, Castellanos y SangermanJarquín, 2017). Sin embargo, los resultados del presente estudio muestran que el ingreso proveniente de actividades agrícolas sigue siendo importante para las familias entrevistadas. La mitad de los caficultores percibieron ingresos provenientes principalmente de actividades agrícolas, en especial del café. Muchos de ellos (42\%) se dedican exclusivamente a este cultivo, esto representa una alta cifra de familias especializadas y repercute en una vulnerabilidad de las condiciones de vida (Escalante et al., 2007) cuando disminuye la producción del cafetal o baja el precio del grano. Por lo general, la intensificación de la producción de café y la especialización en esta actividad ocurre en tiempos de buenos precios, 
cuando se abre la frontera agrícola y cambia el uso del suelo o los caficultores compran tierras para cultivar mayores superficies con café. Sin embargo, en tiempos de bajos precios algunas de estas áreas, en especial las que se encuentran más lejanas a la casa habitación, se abandonan temporalmente y entran en una etapa de reserva mientras la familia se reorganiza y se dedica a otras actividades (Benítez, Soto, Estrada y Pat, 2019).

Cabe mencionar que 11 \% de las familias opta por la pluriactividad. Es decir, comúnmente se tienen tres fuentes principales de ingreso, por tal razón se esperaría que, al invertir tiempo en distintas actividades, las familias pluriactivas hubieran obtenido menor producción en sus cafetales, sin embargo no existe una relación significativa entre mayor especialización y mayor producción. Otros $(42,5 \%)$, combinan la actividad agrícola con actividades fuera de la parcela o en comunidades cercanas como una estrategia para enfrentar las crisis (Carton de Grammont, 2009). Por lo que se sostiene que las familias caficultoras que tienen fortalecido su capital humano y social -a través de la cohesión, organización y cooperación dentro de la familia y la vinculación de esta con redes locales- se benefician de la pluriactividad. Esto se debe a que la distribución de actividades y organización familiar permite tener más opciones como fuentes de ingreso y, a su vez, mantienen atención en las estrategias productivas que requiere el cafetal para ser productivo. Asimismo, la participación en redes locales facilita a la familia el comercio de sus productos agrícolas y en caso de necesidad les permite localizar con mayor facilidad oportunidades de trabajo asalariado, por lo que esta flexibilidad dada brinda resiliencia al sistema.

La estrategia de las familias de tener diversidad de usos de suelo varía en función de las condiciones de la caficultura en la región. $42 \%$ de caficultores está especializado en el cultivo del café y no tiene milpa. Algunos perdieron sus huertos familiares y otros agroecosistemas al desplazarlos para destinar más espacio al cultivo del café, ejemplo de ello es el hecho de que en algunos casos el espacio destinado para cultivar hortalizas y frutales en el hogar se reemplazó por viveros para los semilleros y plántulas de café o para los patios de secado, lo cual generó una mayor vulnerabilidad (Benítez et al., 2019; Escobar, Soto, Estrada, Ishiki-Ishihara, 2019). La eliminación de espacios para la producción de cultivos de autoabasto reduce la posibilidad de producción y reproducción de la familia cafetalera. Reduce también la disponibilidad y diversidad de alimentos lo cual puede derivar en la modificación de la dieta tradicional, como ha sido documentado por otras investigaciones en familias caficultoras de la región (Benítez et al., 
2019; Escobar et al., 2019). La disminución de la diversidad a nivel parcela y paisaje (distintos usos del suelo) reduce la resiliencia de las familias en periodos de crisis, pues se vuelven más dependientes de un solo producto y más vulnerables en las emergencias como los bajos precios, la incidencia de plagas y enfermedades y la variabilidad del clima (Biggs et al.,2015).

La diversificación de especies de sombra y de sotobosque del cafetal implica que las familias decidan cultivar otros productos, como aguacates, cítricos y frutales. De esta manera, se reduce el riesgo de depender de un solo cultivo. Sin embargo, estos cultivos presentan también sus propias amenazas climáticas, plagas, enfermedades y riesgo de mercados (Flores, Soto, Tinoco y Castillo, 2019). El tema de la diversidad y cobertura de sombra en el cafetal es también controversial, sobre todo en relación con la infestación de la roya (Soto, 2019a). No obstante, se ha documentado que un mayor número de estratos en el cafetal, en particular de arbustos de especies distintas al cafeto, es un asociado a la reducción de roya en una parcela (Soto, Perfecto, Caballero-Nieto, 2002). La producción de café orgánico en parcelas diversas favorece tanto la heterogeneidad y multifuncionalidad (Toledo y Barrera-Bassols, 2008), como la existencia de servicios ecosistémicos como el de autorregulación de plagas y enfermedades dado por la interacción entre especies (Perfecto et al., 2014). Los cafetales con estructuras más diversas y complejas se consideran más resilientes ante perturbaciones (Soto, 2019b).

Los productores mantienen distintas variedades de café ante las incertidumbres climáticas y la incidencia de enfermedades del cafeto. Se ha documentado que una mayor diversidad genética puede beneficiar el manejo de plagas y patógenos, más allá de la crisis ocasionada por la roya del cafeto (Ward et al., 2017); pero esto implica otros problemas, como la dificultad de cosechar y procesar el café debido a las diferencias en peso y tamaño de grano, requerimientos técnico-ambientales y calidades entre las distintas variedades. También es importante señalar que la renovación con nuevas variedades representa un reto técnico para los caficultores pues requieren prácticas de manejo distintas a las tradicionales (Henderson, 2019).

El trabajo productivo y reproductivo de las familias campesinas retroalimenta la diversidad y diversificación a través de la creatividad y de procesos de innovación. Junto con las condiciones ambientales, los procesos de innovación son los responsables de los agroecosistemas diversos, en particular del sistema 
productivo de café con sombra diversificada que contribuye a la generación de una matriz del paisaje compleja en el territorio cafetalero (Boege, 2008; Toledo y Barrera-Bassols, 2008; Soto, 2019b). Asimismo, el manejo del territorio, a través de los saberes locales, es importante para la promoción de la diversidad genética, implementación de policultivos y el establecimiento de variedad de prácticas productivas. Estos saberes locales son construidos a partir de la observación y experimentación, y de la coevolución del subsistema social y el subsistema ecológico (Toledo, 2005). El manejo diversificado del territorio es importante para la promoción de la sustentabilidad fundamentada en la resiliencia del sistema (Toledo, 2005; Toral, Palma y González, 2014). La caficultura en México -en especial la realizada por campesinos minifundistas, que producen café orgánico bajo sombra- se caracteriza por estar asociada a la biodiversidad (Moguel y Toledo, 2004; Manson, López, Sosa y Ortega, 2018).

Los sistemas que presentan heterogeneidad de componentes generalmente son más resilientes que los sistemas que tienen mayor homogeneidad en su composición. Ello debido a que la redundancia que provee la diversidad funciona como respaldo en caso de que un componente del sistema se vea afectado (Kotschy, Biggs, Daw, Folke y West, 2015). Sin embargo, la diversidad tiene un costo asociado a la pérdida de eficiencia del sistema. En específico en relación con la dimensión social (Kotschy et al., 2015), en este sentido, la clave para que la diversificación -a través de las distintas estrategias - conduzca a la resiliencia del sistema es la cohesión y organización familiar y la administración de los acervos familiares durante los periodos de estabilidad y de crisis.

En síntesis, las crisis son emergencias que sufren los sistemas socioambientales ante las cuales los campesinos generan mecanismos y estrategias para persistir, resistir, ser resilientes y continuar cultivando café y reproduciendo sus modos de vida en altibajos de buenos tiempos y no tan buenos. Las estrategias desplegadas pueden contribuir a la sobrevivencia campesina (Martínez y Rendón, 1985; Mora-Delgado, 2007; Mora-Delgado, 2008; Cadena, Itandehui, Rendón, Rangel, Salinas y Fernández, 2016) y otras más generan resiliencia, la capacidad de mantener y/o fortalecer la familia, el bienestar y sus acervos a través del amortiguamiento de los impactos, la adaptación y/o transformación (Walker et al., 2004; Biggs et al., 2015). Los campesinos más organizados generan procesos de resistencia y confrontan las relaciones del poder a través de la resignificación y transformación de las condiciones adversas buscando la modificación de 
las asimetrías del poder (Arias, 2014). Los resultados obtenidos concuerdan con Aguilar-Stoen et al. (2011), quienes señalan que los campesinos poseen un fuerte arraigo a su tierra, lo cual permea en la capacidad de persistir siendo cafetaleros.

\section{Consideraciones finales}

A pesar de las crisis que ha enfrentado el sistema -y de los problemas que actualmente enfrentan- las familias campesinas siguen cultivando café. En este estudio se encontró que entre las principales problemáticas los caficultores destacan: el ataque de enfermedades del café, los impactos climáticos en la productividad, la falta de recursos económicos, los bajos precios del grano, la falta de mano de obra y el quiebre generacional.

Ante estas amenazas, los productores han desplegado distintas estrategias derivadas de mecanismos sociales de coordinación, innovación tecnológica, creencias y diversificación. La diversidad de usos del suelo, de germoplasma, de conocimientos y prácticas agroecológicas en el cultivo del café orgánico, así como la diversificación de productos y de actividades son las principales estrategias encontradas en este en este trabajo. Estas contribuyen a la resiliencia de las familias y de los sistemas socioambientales y reducen la vulnerabilidad y el riesgo de los impactos que genera la dependencia de cultivar solo café, también elevan los ingresos y aumentan la flexibilidad y disponibilidad de recursos genéticos. En este sentido, la diversificación es fundamental para la promoción de la sustentabilidad y resiliencia de las familias campesinas. No obstante, estas estrategias no están libres de condicionantes, ya que su contribución a la resiliencia dependerá de las condiciones en las que operen, es decir, de cómo la familia utilice sus acervos físicos, económicos, naturales, humanos, sociales y culturales.

Las familias caficultoras no solo persisten, sino que también resisten. Tienen que confrontar las relaciones de poder que se dan entre la misma familia, las comunidades, las organizaciones, el gobierno y el mercado (intermediarios y empresas). En otros casos son resilientes, ya que se mantienen siendo caficultores, pero se transforman a través de la diversificación, buscando elevar su bienestar familiar. 


\section{Agradecimientos}

Se agradece al Consejo Nacional de Ciencia y Tecnología por el apoyo económico. Especialmente se agradece a la FIECH, a sus socios, y a la Lic. Liliana Rendón por el apoyo con la elaboración del mapa.

\section{Bibliografía citada}

Adger, Neil. (2000). Social and ecological resilience: are they related? Progress in Human Geography, 24(3), pp. 347-364.

Aguilar-Støen, Mariel, Arild Angelsen, Kristi Stølen y Moe Stein. (2011). The Emergence, Persistence, and Current Challenges of Coffee Forest Gardens: A Case Study From Candelaria Loxicha, Oaxaca, Mexico. Society \& Natural Resources: An International Journal, 24 (12), pp. 1235-1251.

Altieri, Miguel. (2013). Construyendo resiliencia socio-ecológica en agroecosistemas: algunas consideraciones conceptuales y metodológicas. En Clara Nicholls, E. Leonardo Ríos Osorio y Miguel Altieri (Eds.). Agroecología y resiliencia socioecológica: adaptándose al cambio climático. Colombia: Red Iberoamericana de Agroecología para el Desarrollo de Sistemas Agrícolas Resilientes al Cambio Climático (REDAGRES)/ CYTED/ SOCIA.

Arias López, Beatriz. (2014). La potencia de la noción de resistencia para el campo de la salud mental: Un estudio de caso sobre la vida campesina en el conflicto armado colombiano. Salud Colectiva, 10 (2), pp. 201-211.

Arteaga, Catalina. (2007). Pobreza y estrategias familiares: debates y reflexiones. Rev. Mad. Revista del Magíster en Análisis Sistémico Aplicado a la Sociedad, (17), pp. 144-164.

Ayala-Carrillo, María del Rosario, Emma Zapata- Martelo, Blanca Suárez- San Román y Austreberta Nazar-Beautelspacher. (2014). Estrategias de reproducción familiar en las fincas cafetaleras del Soconusco, Chiapas. Agricultura, Sociedad y Desarrollo, 11, pp. 401-423.

Bacon, Christopher, William Sundstrom, Iris Stewart y David Beezer. (2017). Vulnerability to Cumulative Hazards: Coping with the Coffee Leaf Rust Outbreak, Drought, and Food Insecurity in Nicaragua. World Development, 93, pp. 136-152.

Barrera, Juan Francisco, Gabriela Huerta, Joel Herrera, Jaime Gómez y Jacques Avelino. (2013). La roya del café, crónica de una devastación anunciada. Ecofronteras, (49), pp. 22-25, disponible en http://revistas.ecosur.mx/ecofronteras/index.php/eco/ article/view/378

Bathfield, Benjamin, Pierre Gasselin, Luis García-Barrios, Remy Vandame y Santiago López-Ridaura. (2015). Understanding the long-term strategies of vulnerable small-scale farmers dealing with markets' uncertainty. The Geographical Journal, 182(2), pp. 165-177, doi: 10.1111/geoj.12142 
Benítez, Marina, Lorena Soto, Erin Estrada, Lucio Pat. (2019). Huertos familiares o sitios en la Sierra Madre de Chiapas. Potencial para la soberanía alimentaria. En Erin Bello, Lorena Soto, Graciela Huerta y Jaime Gómez (Eds.). Caminar el cafetal: Perspectivas socioambientales del café y su gente. México: El Colegio de la Frontera Sur/ Juan Pablos.

Biggs, Reinette, Maja Schluter y Michael Schoon. (2015). An introduction to the resilience approach and principles to sustain ecosystem services in social-ecological systems. En Renette Biggs, Maja Schluter y Michael Schoon (Eds.). Principles for Building Resilience Sustaining Ecosystem Services in Social-Ecological Systems. Cambridge: Cambridge University Press.

Boege, Eckart. (2008). El patrimonio biocultural de los pueblos indígenas de México: hacia la conservación in situ de la biodiversidad y agrodiversidad en los territorios indígenas. México: Instituto Nacional de Antropología e Historia/CNDI.

Boudon, Raymond. (2006). Social Mechanisms without Black Boxes. En Peter Hedström, Richard Swedberg (Eds.). Social Mechanisms: An Analytical Approach to Social Theory, pp. 172-203. Cambridge: Cambridge University Press.

Bourdieu, Pierre. (2002). Estrategias de reproducción y modos de dominación. Colección Pedagógica Universitaria, enero-julio, (37-38).

Buchmann, Christine. (2009). Cuban Home Gardens and Their Role in Social-Ecological Resilience. Human Ecology, 37, pp. 705-721, doi: 10.1007/s10745-009-9283-9

Bunge, Mario. (2000). La relación entre la Sociología y la Filosofía. España: Editorial EDAF. Bunge, Mario. (2004). How Does It Work? The Search for Explanatory Mechanisms. Philosophy of the Social Sciences, 34 (2), pp. 182-210.

Cadena, Iñiguez Pedro, Leyva Karina Itandehui Garrido; Roberto Rendón Medel, Jaime Rangel Quintos, Eileen Salinas Cruz e Isidro Fernández González. (2016). Persistencia campesina: estrategias de vida en áreas marginadas de Chiapas. Revista Mexicana de Ciencias Agrícolas, 7 (4), mayo-junio, pp. 809-819.

Carton de Grammont, Hubert. (2009). La desagrarización del campo mexicano. Convergencia. Revista de Ciencias Sociales, mayo-agosto, 16 (50), pp. 13-55.

Carton de Grammont, Hubert. (2016). Hacia una ruralidad fragmentada La desagrarización del campo mexicano. Nueva Sociedad, marzo-abril, (262).

Carton de Grammont, Hubert y Luciano Martínez. (2009). La pluriactividad en el campo latinoamericano. Ecuador: FLACSO.

Comité Estatal de Información Estadística y Geográfica (CEIEG). (2015). Conjunto de datos vectoriales de Localidades del año 2015. Escala 1: 250 000, disponible en: http:// map.ceieg.chiapas.gob.mx/geoweb/

Chayanov, Alexander. (1974). La organización de la unidad económica campesina. Buenos Aires, Argentina: Ediciones Nueva Visión SAIC.

Comisión Nacional para el Conocimiento y Uso de la Biodiversidad (CONABIO). (2016). Conjunto de Datos Vectoriales de Uso de Suelo y Vegetación. Serie VI (Capa Unión). Escala 1:250 000, disponible en: http://www.conabio.gob.mx/informacion/metadata/gis/usv250s6gw.xml?_httpcache=yes\&_xsl=/db/metadata/xsl/fgdc_html. xsl\&_indent=no 
Eakin, Hallie, Catherine Tucker, Edwin Castellanos, Rafael Díaz-Porras, Juan F. Barrera y Helda Morales. (2013). Adaptation in a multi-stressor environment: perceptions and responses to climatic and economic risks by coffee growers in Mesoamerica. Environment, Development and Sustainability, 16 (1).

Eakin, Hallie, Luis Bojórquez-Tapia, Rafael Monterde Diaz, Edwin Castellanos y Jeremy Haggar. (2011). Adaptive Capacity and Social-Environmental Change: Theoretical and Operational Modeling of Smallholder Coffee Systems Response in Mesoamerican Pacific Rim. Environmental Management, 47, pp. 352-367, doi: 10.1007/s00267-010-9603-2

Ellis, Frank. (1998). Household strategies and rural livelihood diversification. The Journal of Development Studies, 35 (1).

Escalante, Roberto, Horacio Catalán, Luis M. Galindo y Orlando Reyes. (2007). Desagrarización en México: tendencias actuales y retos hacia el futuro. Cuadernos de Desarrollo Rural, julio-diciembre, (59), pp. 87-116

Escamilla, Esteban, Octavio Ruiz, Gabriel Díaz, Cesáreo Landeros, D.E. Platas, Alfredo Zamarripa, Víctor González. (2005). El agroecosistema café orgánico en México. Manejo Integrado de plagas y Agroecología, 76, pp. 5-16.

Escobar-Colmenares, Sandra, Lorena Soto Pinto, Erin Estrada Lugo y Mario Ishiki-Ishihara. (2019). Agroecosistemas y alimentación de grupos domésticos cafetaleros en una comunidad de la Sierra Madre de Chiapas. En Ana Isabel Moreno Calles, Lorena Soto Pinto, Marta Micheline Cariño O., José Manuel Palma García, Sergio Moctezuma P., Jesús Juan Rosales A., Patricia Irene Montañez E., Vinicio de Jesús Sosa, María del Rocío Ruenes M. (Eds). Los Sistemas Agroforestales de México: Avances, experiencias, acciones y temas emergentes en México, pp. 618-64. México: Universidad Nacional Autónoma de México.

Falleti, Tulia y Julia Lynch. (2009). Context and Causal Mechanisms in Political Analysis. Comparative Political Studies, 42 (9), pp. 1143-1166.

Figueroa, Esther, Francisco Pérez y Lucila Godínez. (2015). La producción y consumo del café. España: ECORFAN.

Flores, José Luis, Lorena Soto Pinto, Juan Ángel Tinoco y Miguel Ángel Castillo. (2019). Oportunidad para diversificar las zonas cafetaleras de la Sierra Mariscal de Chiapas ante el cambio climático. En Erin Bello, Lorena Soto, Graciela Huerta y Jaime Gómez (Eds.). Caminar el cafetal: Perspectivas socioambientales del café y su gente. México: El Colegio de la Frontera Sur/ Juan Pablos.

Folke, Carl. (2006). Resilience: The emergence of a perspective for socio-ecological systems analyses. Global Environmental Change, 16, pp. 253-267.

Folke, Carl, Filkret Berkes y Johan Colding J. (1998). Ecological practices and social mechanisms for building resilience and sustainability. En Berkes Filkret, Carl Folke y Johan Colding (Eds.), Linking social and ecological systems: management practices and social mechanisms for building resilience, pp. 414-436. Cambridge: Cambridge University Press.

Frank, Elisa, Hallie Eakin y David López-Carr. (2011). Social identity, perception and motivation inadaptation to climate risk in the coffee sector of Chiapas, Mexico. Global Environmental Change, 21, pp. 66-76. 
Gibert, Jorge. (2014). Ontología social y el problema de los mecanismos. Eikasia: Revista de Filosofía, (54).

González, Felipe. (2016). Los mecanismos sociales y su relación con la distinción micro-macro. Cinta moebio, 55, pp. 16-28, disponible en: www.moebio.uchile.cl/55/ gonzalez.html

González-Jácome, Alba. (2004). Ambiente y cultura en la agricultura tradicional de México: casos y perspectivas. Ciencia Ergo Sum, 11 (2), julio-octubre, pp. 153-163.

Gross, Neil. (2009). A pragmatist theory of social mechanisms. American Sociological Review, 74, pp. 358-379.

Gunderson, L., C. Holling, L Pritchard y G. Peterson. (2002). Resilience of Large-Scale Resource Systems. En Lance Gunderson y Lowell Pritchard (Eds.). Resilience and Behavior of Large- Scale Systems. USA: SCOPE 60/Island Press.

Hausermann, Heidi. (2014). Mantaining the coffee canopy: Understanding change y continuity in Central Veracruz. Human Ecology, 42, pp.381-394.

Hedström, Peter y Richard Swedberg. (2006). Social mechanisms: An introductory essay. En Peter Hedström, Swedberg Richard (Eds.). Social mechanisms: An Analytical Approach to Social Theory. Cambridge: Cambridge University Press.

Hedström, Peter. (2006). Explaining Social Change: An Analytical Approach. Papers: revista de sociología, (80), pp. 73-95.

Henderson, Thomas. (2019). La roya y el futuro del café en Chiapas. Revista Mexicana de Sociología, abril-junio, 81 (2).

Instituto Nacional de Estadística y Geografía (INEGI). (2008). Conjunto de datos vectoriales de unidades climáticas. Escala 1:1 000 000, disponible: https://www.inegi.org. $\mathrm{mx} /$ temas/climatologia/default.html\#Descargas

Instituto Nacional de Estadística y Geografía (INEGI). (2014). Conjunto de Datos Vectoriales de Edafología (Serie II). 1:250 000, disponible: https://www.inegi.org.mx/temas/edafologia/default.html\#Descargas

Instituto Nacional de Estadística y Geografía (INEGI). (2017). Conjunto de datos vectoriales de la carta de Uso del suelo y vegetación serie VI. Conjunto Nacional. Escala 1: 250 000, disponible en: https://www.inegi.org.mx/temas/usosuelo/default. html\#Descargas.

Jarquín Sánchez Natalia, José Castellanos Suárez y Dora Sangerman-Jarquín. (2017). Pluriactividad y agricultura familiar: retos del desarrollo rural en México. Revista Mexicana de Ciencias Agrícolas, 8 (4), mayo-junio, pp. 949-963.

Kalawski Juan P.y Ana Haz. (2003). Y... ¿ Dónde Está la Resiliencia? Una Reflexión Conceptual. Revista Interamericana de Psicología/Interamerican Journal of Psychology, 37 (2), pp. 365-372.

Kotschy K., R.Biggs, T. Daw, C. Folke, P. West. (2015). Principle 1 - Maintain diversity and redundancy. En R. Biggs, M. Schluter y M. Schoon. (Eds). Principles for Building Resilience Sustaining Ecosystem Services in Social-Ecological Systems. Cambridge: Cambridge University Press

Levy, Samuel, José Oleta, Karen Odriozola, Manuel Parra, Juan Manuel Pat, Neptalí Ramírez, Laura Rubio, Lorena Soto, Romeo Trujillo, Abril Valdivieso, Remy Vandame, Erick Vides y María Eugenia Escobar. (2012). ¿Cómo nos organizamos para la inno- 
vación socioambiental? En Eduardo Bello, Eduardo Naranjo y Remy Vandame (Eds.). La otra innovación para el ambiente y la sociedad en la frontera sur de México, pp. 20-24. México: ECOSUR.

Machado-Vargas, Mónica, Clara Nicholls-Estrada y Leonardo Ríos-Osorio. (2018). Social-ecological resilience of small-scale coffee production in the Porce river basin, Antioquia (Colombia). Idesia (Arica), 36(3), pp. 141-151, doi: https://dx.doi. org/10.4067/S0718-34292018005001801

Manson, Robert, Fabiola López, Vinicio Sosa y Aline Ortega. (2018). Biodiversidad y otros servicios ambientales en cafetales: manual de mejores prácticas. México: CONABIO.

Martínez, Marielle y Teresa Rendón. (1983). Organización familiar de trabajo y estrategias de reproducción; las unidades domésticas en el espacio local. En Kirsten Appendini, P. Marielle, L. Martínez, Teresa Rendón y Vania A. de Salles (Eds.). El campesinado en México: dos perspectivas de análisis. México: El Colegio de México.

Moguel, Patricia y Víctor Toledo. (2004). Conservar produciendo: Biodiversidad, café orgánico y jardines productivos. Biodiversitas, 55.

Mora-Delgado, Jairo. (2007). Sociedades campesinas, agricultura y desarrollo rural. Revista Luna Azul, (24), pp. 52-58.

Mora-Delgado, Jairo. (2008). Persistencia, conocimiento local y estrategias de vida en sociedades campesinas. Revista de Estudios Sociales, (29), pp. 122-133.

Mora, José y Hazael Cerón. (2015). Diversificación de ingresos en el sector rural y su impacto en la eficiencia: evidencia para México. Cuadernos de Desarrollo Rural, julio-diciembre, 12 (76).

Nájera, Olivia. (2002). El café orgánico en México. Cuadernos de Desarrollo Rural, (48), disponible en: http://www.redalyc.org/articulo.oa?id=11704804

Olsson, Per, Carl Folke y Thomas Hahn. (2004). Social-ecological transformation for ecosystem management: the development of adaptive co-management of a wetland landscape in southern Sweden. Ecology and Society, 9(4), disponible en: http:// www.ecologyandsociety.org/vol9/iss4/art2

Pérez Monterosas, Mario. (2018). Las migraciones en el norte de Veracruz, México. Redes, rutas y ruralidades. Si Somos americanos, 18(2), 34-52, doi: https://dx.doi. org/10.4067/S0719-09482018000200034

Pérez-Pérez, Eliezer y Daniel Villafuerte-Solís. (2018). Efectos del mercado desregulado sobre los campesinos productores de café de Los Altos de Chiapas: el caso de UCIPA. Revista LiminaR. Estudios Sociales y Humanísticos, XVI (1), enero-junio pp. 134-149.

Perfecto, Ivette, John Vandermeer, Stacy Philpott. (2014). Complex Ecological Interactions in the Coffee Agroecosystem. Annual Review of Ecology, Evolution, Systematics, 45, noviembre, pp. 137-158, doi: 10.1146/annurev-ecolsys-120213-091923.

Perz Stephen, Rafael Muñoz- Carpena, Gregory Kiker y Robert Holt. (2013). Evaluating ecological resilience with global sensivity and uncertainty analysis. Ecological Modelling, 263, pp. 174-186.

Pierson, Paul. (2000). Not Just What, but When: Timing and Sequence in Political Processes. Studies in American Political Development, 14, pp. 72-92. 
Renau, Juan José. (1977). Innovación y previsión tecnológica: principales modelos. Revista Española de Financiación y Contabilidad, 6 (22), pp. 681, 683-696.

Rodríguez, Benigno y Kees Burger. (2015). Diversification and labor market effects of the Mexican coffee crisis. World Development, 68, pp. 19-29.

Sánchez Juárez, Gladys Karina. (2015). Participación campesina en el mercado global de café: Cafeticultores organizados en Chiapas. Nóesis. Revista de Ciencias Sociales y Humanidades, 24.

Santacruz de León, Eugenio y Elba Pérez Villalba. (2009). Atraso económico, migración y remesas: el caso del Soconusco, Chiapas, México. Convergencia: Revista de Ciencias Sociales, (50), mayo-agosto, pp. 57-77.

Secretaría de Desarrollo Social (SEDESOL). (2013). Catálogo de localidades, disponible en: http://www.microrregiones.gob.mx/catloc/LocdeMun.aspx (consulta: 12/2019).

Soto Pinto, Lorena, Ivette Perfecto, Javier Caballero-Nieto. (2002). Shade over coffee: Its effects on berry borer, leaf rust and spontaneous herbs in Chiapas, Mexico. Agroforestry Systems, 55(1), pp. 37-45, doi: https://doi.org/10.1023/A:1020266709570

Soto Pinto, Lorena. (2019a). Entre el dilema de producir café y mantener los beneficios socioambientales del cafetal. En Eduardo Bello, Lorena Soto Pinto, Graciela Huerta, Jaime Gómez (Eds.). Caminar el cafetal. Perspectivas socioambientales del café y su gente, pp 239-251. México: ECOSUR/Juan Pablos Editores.

Soto Pinto, Lorena. (2019b). La importancia de la sombra del café en la productividad, la roya y los servicios ambientales. En Eduardo Bello, Lorena Soto Pinto, Graciela Huerta, Jaime Gómez (Eds.). Caminar el cafetal. Perspectivas socioambientales del café y su gente, pp 239-251. México: ECOSUR/Juan Pablos Editores.

Toledo, Víctor M. (2005). La memoria tradicional: la importancia agroecológica de los saberes locales. LEISA. Revista de Agroecología, 20(4).

Toledo, Víctor M. y Narciso Barrera-Bassols. (2008). La memoria biocultural: la importancia ecológica de las sabidurías tradicionales. España: Icaria Editorial.

Tompkins, Emma y Neil Adger. (2004). Does adaptive management of natural resources enhance resilience to climate change? Ecology and Society. 9(2), disponible en: http://www.ecologyandsociety.org/vol9/iss2/art10

Toral, José, José Palma y Eliel González. (2014). La adaptación como atributo esencial en el fomento de sistemas agropecuarios resilientes ante las perturbaciones. Avances en Investigación Agropecuaria, 18 (3), pp. 7-34.

Valencia, Vivian, Luis García-Barrios, Eleanor Sterling, Paige West, Amayrani MezaJiménez y Shahid Naeeme. (2018). Smallholder response to environmental change: Impacts of coffee leaf rust in a forest frontier in Mexico. Land Use Policy, 79, pp. 463-474.

Van Oostrom, Madelon y Manuel Fernández-Esquinas. (2017). Exploring the links between culture and innovation in micro firms: cultural dimensions, social mechanisms and outcomes. European Planning Studies, 25 (11), pp. 1932-1953, doi: 10.1080/09654313.2017.1355355

Villafuerte, Solís, David. (2015). Transformaciones socioeconómicas y neo-extractivismo en Chiapas. Argumentos, septiembre-diciembre, 28 (79), pp. 191-213. 
Walker, Brian, C. Holling, Stephen Carpenter y Ann Kinzig. (2004). Resilience, Adaptability and Transformability in social-ecological systems. Ecology and Society, 9(2), pp. 5.

Ward, Rachel, David Gonthiera y Clara Nicholls. (2017). Ecological resilience to coffee rust: Varietal adaptations of coffee farmers in Copán, Honduras. Agroecology and Sustainable Food Systems, 41 (9-10), pp. 1081-1098, doi: https://doi.org/10.1080/ 21683565.2017.1345033

\section{Cómo citar este artículo:}

Nenegas, Andrea, Lorena Soto, Guadalupe Álvarez, Armando Alayón y Emmanuel Díaz. (2021). La diversificación de estrategias socioambientales en la familia campesina: mecanismo de resiliencia ante la crisis del café en Chiapas. Revista Pueblos y fronteras digital, 16, pp.1-31, doi: 10.22201/cimsur.18704115e.2021.v16.510 